\title{
LIMITES À FUNÇÃO SANCIONATÓRIA DAS AGÊNCIAS REGULADORAS DE SERVIÇOS PÚBLICOS
}

\author{
LIMITS TO THE SANCTIONING FUNCTION OF THE PUBLIC UTILITIES \\ REGULATORY AGENCIES
}

${ }^{1}$ Sérgio Luiz Barbosa Neves

\section{RESUMO}

Dentre as diversas funções das agências reguladoras, a sancionatória é a menos estudada. A doutrina limita-se a reconhecer a legitimidade das agências reguladoras para aplicar sanções decorrentes de sua atividade fiscalizatória, esquecendo-se, entretanto, de examinar a questão sob o aspecto de uma lógica amplificada como a da regulação, que se apropria de princípios outros além dos do Direito Administrativo, buscando funcionalizar as decisões proferidas por seus órgãos colegiados, sob forte influência do Direito Econômico. Essa forma de decidir é mais adequada à dinamicidade das relações sociais atuais e aos quase que cotidianos avanços tecnológicos, num mundo em constante mutação e pautado por heterogeneidades interdependentes. A aplicação de multas pecuniárias apresenta-se como uma solução simplória de âmbito contratual, que não satisfaz o objetivo maior da regulação de serviços públicos, que é o de assegurar a sua permanente adequação, tal como previsto pelo art. $6^{\circ}$, da Lei $n^{\circ} 8.987 / 95$.

Palavras-chave: Agência reguladora, Direito econômico, Sanções, Serviço público adequado

\begin{abstract}
Among the various functions of the regulatory agencies, the sanctioning is less studied. The doctrine limits itself recognizing the legitimacy of regulators to impose sanctions arising from its inspection activity, forgetting, however, to examine the issue from the aspect of an amplified logic as the regulation, which appropriates other principles beyond the Administrative Law, seeking to functionalize the decisions issued by its collegiate bodies, under strong influence of Law and Economics. This decision making method is best suited to the dynamics of current social relations and to the almost daily technological advances in a world constantly changing and marked by interdependent heterogeneities. The imposition of fines is therefore a simple solution under contractual rules, which does not meet the main goal of public utility regulation, which is to ensure its adequacy, as provided for by art. 6 of Law No. 8,987 / 95.
\end{abstract}

Keywords: Regulatory agency, Law and economics, Sanctions, Adequate public utilities

\footnotetext{
${ }^{1}$ Mestre em Direito pela Pontifícia Universidade Católica do Paraná - PUC/PR, Paraná (Brasil). Professor do Curso de Pós-Graduação da Universidade Candido Mendes, Rio de Janeiro (Brasil). E-mail: sergiolbn@bol.com.br
} 


\section{INTRODUÇÃO}

As agências reguladoras são prolíficas em fornecer temas de estudo para a ciência jurídica. Passados vinte anos de sua criação, vários de seus aspectos foram examinados com vigor, todavia e não raro, apresentam-se novos questionamentos concernentes à sua atuação.

A atividade regulatória compreende uma plêiade de funções como a administrativa e a normativa, sendo que, essa última, é aquela sobre a qual a doutrina mais se debruçou. Outra função é a jurisdicional em âmbito administrativo, cujo exercício permite às agências julgar situações que envolvam, por exemplo, alguma falha na prestação dos serviços pelas concessionárias. Essa função jurisdicional está relacionada para com uma atividade fiscalizatória prévia, que tanto detecta falhas prévias como apura a causa de acidentes. De fato, todas as leis criadoras das agências reguladoras de serviços públicos atribuem-lhes a fiscalização da prestação desses serviços pelas respectivas concessionárias e, quanto a isso, divergências doutrinárias não houve. Todavia, é do exercício dessa atividade fiscalizatória que nasce para a agência reguladora a possibilidade de impor sanções administrativas às empresas concessionárias. Tais sanções resumem-se, invariavelmente, à aplicação de multas pecuniárias. Haveria nesse tema alguma novidade, digna de nota?

Uma resposta positiva ou negativa depende da forma pela qual se compreende o que é agência reguladora e o que se tem por precípuo no exercício da atividade regulatória. Se, tal como prepondera na doutrina, se tem como inerentes às agências reguladoras características próprias como independência político-administrativa e financeira, órgão deliberativo colegiado e dotado de mandato e um alto nível de capacidade e especialização técnica, para o fim de desempenhar suas funções, jurisdicional, normativa e administrativa, com absoluta neutralidade, eficiência e conformidade socioeconômica, seria diminuir e muito as suas funções entender a atividade regulatória como uma mera atividade fiscalizatória, capaz de redundar em multas pecuniárias. Observe-se uma primeira incongruência, pois, enquanto a atividade fiscalização com apuração de falha/imposição de multa constitui-se num ato vinculado, a regulação é muito mais ampla e não só admite como exige exame socioeconômico do contexto do serviço objeto de regulação. Isto é, tratar a atuação fiscalizatória das agências reguladoras de serviços públicos como uma mera aplicação de regras de subsunção significaria a restrição absoluta da atividade regulatória a uma espécie de 
atividade vinculada da Administração Pública, o que não procede, eis que a regulação, por maior proximidade para com o Direito Econômico, tem por mérito a possibilidade de subverter as normas de subsunção e de adotar soluções para tornar o serviço mais adequado à dinamicidade social, econômica e tecnológica, conferindo um serviço mais seguro, eficiente e de maior qualidade aos usuários, tal como preceituado pelo inciso I do art. $6^{\circ}$, da Lei $\mathrm{n}^{\circ}$ $8.987 / 95$.

Considerando, que, na prática, as agências reguladoras têm sido vítimas de um uso político-partidário por parte dos governos, a redução da atividade regulatória a uma atividade meramente fiscalizatória, com consequente imposição de sanções pecuniárias, passa a ser uma realidade tangível dentro da Administração Pública brasileira.

Situações hipotéticas podem ser, assim, desenvolvidas, no sentido de a questão do exercício da função sancionatória ser melhor examinada em relação ao exercício da atividade regulatória em toda a sua amplitude. Imagine-se, por exemplo, a prestação de um serviço de transporte ferroviário, onde a concessionária adquiriu os materiais e peças de reposição especificados no contrato, procedeu à sua troca e manutenção, dentro dos períodos de previstos contratualmente, sendo tudo acompanhado e atestado pelos fiscais da agência reguladora, como de conformidade para com o contrato de concessão. Durante a execução do serviço, uma dessas peças sofre avaria e esse passa a operar com atraso significativo, em prejuízo para os usuários. A falha, atraso das composições ferroviárias em prejuízo dos usuários, pode ser causa de imposição de sanção conforme cláusula contratual, porém, nessa hipótese, a sanção poderia ser aplicada? E se as avarias de determinadas peças se repetem e vários atrasos são constatados durante um período de tempo relativamente curto, seria justa a aplicação de sanções, ainda que se descobrisse que as peças, contratualmente previstas, não eram adequadas à prestação do serviço na atualidade ou que houve alguma espécie de sabotagem por terceiros? Os atrasos também poderiam ser determinados pelo simples aumento populacional e de usuários do sistema ferroviário numa certa região, onde as estações não mais comportassem o movimento e entrassem em colapso, embora todas as cláusulas contratuais de investimentos e incrementos na infraestrutura estivessem a ser observadas. Em alguns casos seria de indagar-se, inclusive quanto a possibilidade de sanções serem impostas pela agência à Administração Pública que a criou, tal como proceder à alteração de um contrato de concessão ou a prática de um ato contratualmente previsto, como por exemplo, a aprovação de um cronograma financeiro apresentado pela concessionária sujeito a algum termo já expirado, caracterizando, pois, a omissão do poder concedente. 
Observe-se que não se está a discutir situações em que a empresa falha efetivamente na prestação do serviço, mas sim hipóteses em que a agência reguladora detecta que a falha aconteceu apesar do próprio e correto cumprimento do contrato. Resumir a atividade regulatória, nesses casos, a aplicar ou não uma multa consiste, exatamente, na restrição da atividade regulatória a uma atividade meramente de constatação e de produção de atos vinculados. Nessas hipóteses, a agência reguladora estaria a constatar que o contrato previu meios insuficientes ou inadequados à consecução dos fins de eficiência, qualidade e segurança dos serviços. Portanto, a atividade regulatória, a fim de atender a seus escopos precípuos, haveria de ir além, salientando mesmo que o julgamento dessas situações, sequer passa pelo exame da aplicação ou não de sanções.

Cumpre responder à indagação referente à conduta que seria esperada de uma agência reguladora frente a hipóteses como essas.

Nesse passo, se uma agência reguladora verifica a incidência de inúmeras falhas do serviço e se limita a aplicação de multas, que, apesar de ter como didáticas, não inibem novos incidentes e mais multas, a repetição imoderada de decisões dessa espécie estaria a significar uma ineficiência não tanto do serviço, mas da própria regulação em si. Ou seja, o incremento da imposição de multas seria uma espécie de atestado de incompetência da própria agência reguladora em exercer a atividade regulatória.

São fatos como esse que conduziram à construção do presente artigo, que pretende questionar os limites ao exercício dessa atividade sancionatória das agências reguladoras de serviços públicos, pois, como visto, é possível que excessos estejam a demonstrar a sua ineficiência, ao invés de enobrecer a sua atividade regulatória. A questão que se põe é a de como avaliar esses limites à função sancionatória.

Nesse escopo, o artigo passa, primacialmente, pela construção de um conceito de atividade regulatória de serviços públicos e a definição de seu objeto. Em sequência, passa-se ao exame do exercício da função jurisdicional das agências reguladoras e da possibilidade da adoção de medidas consensuais. Adiante e mais especificamente, analisa-se o exercício da função sancionatória pelas agências reguladoras, observando-se e sob o prisma do que dispõe a Lei $n^{\circ} 8.987 / 95$ a respeito da aplicação de sanções às concessionárias, desde advertências até a declaração de caducidade do contrato de concessão e a legitimidade para tal decretar, isto é, se cabe à agência ou se somente o Poder Concedente poderia decretá-la, tal como previsto no art. 38 da referida lei. 
Por fim, pretende-se oferecer conclusões que promovam a adoção de medidas consensuais ou, ainda que impositivas, de medidas que privilegiem melhorias e maiores investimentos na prestação dos serviços públicos concedidos, como soluções sucedâneas à mera e simplória aplicação de sanções pecuniárias. Proporcionalidade e razoabilidade são princípios que devem pautar a atuação das agências no momento do exercício da função sancionatória. Todo o estudo parte do pressuposto de que as agências reguladoras são entes aos quais foi conferida maior autonomia para o desempenho de funções cujo exercício pressupõe um conhecimento técnico absoluto da atividade regulada em nível de expertise técnica refinada, que, ao menos em tese, não é do domínio de nenhuma outra instituição pública.

\section{A ATIVIDADE REGULATÓRIA.}

Incialmente, há de se destacar que a atividade regulatória, diversamente de outras áreas de atuação da Administração Pública sujeitas ao pálio exclusivo do Direito Administrativo, é melhor examinada quando submetida ao olhar amplificado do Direito Econômico. A observação é fundamental para que se possa compreender a lógica de solução de problemas a ser utilizada pela regulação, que será diversa daquela tradicionalmente utilizada pelo Direito. Visto sob o prisma de seus ramos tradicionais, o Direito era enunciado com vistas à relação jurídica havida entre o titular do direito subjetivo e o titular do dever jurídico correspondente. As causas e as consequências próprias de uma relação jurídica eram examinadas de forma intrínseca a esta relação numa lógica própria do primado da individualidade. Neste sentido, a lógica de imputação quando da verificação de uma lesão de direito replicava e aplicava a norma do tipo "Se A é, B deve ser".

FERRAZ (2006, p. 85), tendo por base o Direito Econômico, ensina que aspectos extrínsecos à relação jurídica são relevantes para este ramo, engendrando uma lógica própria e diferenciada. Assim, o Direito Econômico traz uma lógica própria e inovadora, diversa daquela há muito estruturada pelos demais ramos do Direito, inservíveis, em muitos aspectos, à realidade atual da sociedade em sua extrema dinamicidade socioeconômica. Isto é, resta assim justificado que as agências reguladoras podem conceber as normas em seus aspectos macrológicos para fins de compor os conflitos que lhes são submetidos, abstraindo, até certo ponto, os direitos individualmente considerados, compondo a sua decisão em consideração ao 
todo do ambiente regulado, levando em conta os aspectos sociais e econômicos, indo muito além daqueles exclusivamente contratuais.

A potestade pública cede, assim, a uma relação de direção, que, a par de ainda conter o controle, admite novos conceitos como de flexibilização com a flagrante revisão do papel do próprio Estado, eis que, considerada a característica das agências reguladoras, haveria de se submeter às decisões por essas emitidas, sob pena de, em não o fazendo, haver uma total subversão da noção de regulação. Nesse assentir, a relação entre agências reguladoras e regulados pode envolver o controle, mas a busca de soluções a conflitos, ao admitir a flexibilização e a observância macrológica do fato em face das normas legais e contratuais, passa a resolver as disfunções contratuais que importem falhas na prestação do serviço não mais com a simplória imposição de sanções. Ao invés de serem reprimidas com medidas sancionatórias, são eliminadas mediante a adoção de medidas corretivas, frequentemente informais (GIANNINI, 1995, p. 299).

Essas constatações demonstram o forte impacto do Direito Econômico sobre a atividade regulatória, que, para melhor atender à dinamicidade das relações sociais atuais e aos quase que cotidianos avanços tecnológicos, num mundo em constante mutação e pautado por heterogeneidades interdependentes, deve preferir emitir decisões que melhor atendam à realidade posta do que a um conjunto de normas fechado e criado em face de um arquétipo ultrapassado, incapaz de atender a anseios presentes.

Essa conclusão denota o caráter funcional da regulação, que a coloca perante as modernas correntes que pugnam pela funcionalização do próprio Direito. Mais do que produzir atos de composição de conflitos, normativos ou de fiscalização, a atividade regulatória tem um escopo permanente de amoldar a prestação do serviço público regulado a um determinado momento socioeconômico, cuja dinamicidade é indiscutível na atual sociedade da informação. Para tal fim, a regulação vale-se do Direito para fins de funcionalizar as suas normas perante um determinado e momentâneo contexto socioeconômico. A atividade regulatória transcende, pois, ao Direito Administrativo e sua lógica normativa, estampando fortes traços econômicos, de molde a adentrar num campo de subjetivismo ao valer-se, como não pode deixar de ser ao se falar em sua funcionalização, da Sociologia. Vê-se, desta sorte, que não se pode transcender àquela lógica estrutural do Direito Administrativo e passar-se a uma lógica funcional sem que se busque uma contribuição inequívoca da Sociologia, dizendo que "nunca, tanto quanto hoje, a ciência jurídica sentiu a necessidade de estabelecer novos e mais estreitos contatos com as ciências sociais" 
(BOBBIO, 2007, pp. 34 e 37), ou seja, o agente regulador tem de "sair do seu casulo" para que possa enfrentar o problema do Direito na sociedade.

A atividade regulatória é eminentemente jurídica porque regulada por lei, mas é, de forma vanguardista, a sede primeira da funcionalização do Direito e, portanto, conjuga não só a aplicação estruturada de normas e princípios jurídicos, mas, acima de tudo, conjuga-as com normas e diretrizes técnicas, com conceitos e princípios econômicos, bem como com análises sociológicas. Importa, aqui, que a regulação seja coerente para com todo esse contexto principiológico multidisciplinar.

Para a consecução de sua funcionalização, o verdadeiro ato regulatório é multidisciplinar, transcende o jurídico, mas traz para o jurídico o conteúdo econômico, sociológico, antropológico e o tecnológico, entre outros possíveis. $\mathrm{O}$ ato regulatório tem, pois, uma gama de elementos científicos metajurídicos, que comporão a sua razão de ser e que têm de ser examinados por aqueles que se propuserem a aferir a razoabilidade, a proporcionalidade, a moralidade, a eficiência, a economicidade e a impessoalidade desse ato. $\mathrm{O}$ ato regulatório vai além de uma perspectiva da análise econômica do Direito ou de sua legalidade.

Ou seja, trazer para a regulação a velha classificação dos atos administrativos em discricionários e vinculados não traria qualquer contribuição ao exercício da atividade regulatória, que estaria limitada à prática de atos estritamente previstos em lei ou ao exame de motivos de conveniência e oportunidade perante fatos indiferentes à lei. Diante de uma falha no serviço publico objeto da regulação, a agência reguladora pode e deve ter uma atuação bem mais complexa e ampla do que essa consignada nos antigos manuais de Direito Administrativo, buscando ser mais científica, multidisciplinar e refinada perante poder concedente, concessionário e usuários, proferindo decisões em função de um serviço público adequado.

Dentre todas as funções propostas às agências reguladoras, qual seria a que se caracterizaria como atividade regulatória propriamente dita. A qualidade de agência reguladora pressupõe o exercício simultâneo das funções administrativa, jurisdicional e normativa a fim de que possa bem regular um serviço público privatizado (MOTTA, 2003, p. 100). A agência promove funcionários, organiza seus serviços, compra bens e serviços por intermédio de processos licitatórios, edita regulamentos e expede deliberações, por exemplo, mas todos esses atos traduzem atos administrativos exercidos para a consecução de sua atividade-fim, que é a de regular o serviço. A natureza regulatória é exclusiva do ato 
produzido em razão do exercício de uma função própria e exclusiva da agência, isto é, aquele destinado à consecução de sua atividade-fim, o que obriga o jurista a identificar as funções que são típicas das e exclusivas das agências reguladoras.

BRITTO (2005, p.67), distinguindo funções, competências e atribuições, explica função como a "atividade típica de um órgão. Atividade que põe o órgão em movimento e que é a própria justificativa imediata desse órgão (atividade-fim, portanto)" . O escopo maior de uma agência reguladora de sérvios públicos é o de promover e manter a adequação desse serviço. Sendo assim, todos os atos produzidos para esse fim específico têm natureza regulatória.

Dúvida que surge refere-se às sanções porventura impostas às concessionárias como sendo ato regulatório típico ou não. Note-se que uma sanção pode consistir tanto numa multa pecuniária como na realização de um investimento que incremente o serviço. Uma pergunta sobressai: qual a utilidade da multa para a melhoria do serviço? Sobre o tema há de se retornar ao final desse trabalho, já com fins à sua conclusão.

O que cumpre ressaltar é o caráter fundamental da autonomia em relação aos entes reguladores e, por conseguinte, ao ato regulatório. Isto é, a imposição ou não de uma multa seria ato obrigatório para o órgão deliberativo da agência, quando expressamente prevista por uma cláusula de contrato ou estaria sujeito ao exame de sua utilidade e benefício para a regulação do serviço? Uma coisa é certa, só há verdadeira regulação estatal onde autonomia houver, sendo indispensável que a autoridade reguladora seja dotada de independência e estabilidade para a prática do ato (ORTIZ, 2004, P. 642).

Enquanto a criação de autarquias visa a atender uma técnica de descentralização administrativa, é fundamental ressaltar que a criação de agências reguladoras visa algo além, pois a autonomia surge como garantidora da neutralidade, do exercício de poderes normativos e decisórios com plena independência e equidistante de interesses, sejam do Estado, dos concessionários ou dos usuários. A atividade regulatória é exercida a bem do serviço público e não em função de uma política partidária ou de um desejo econômico-financeiro empresarial e tem, na autonomia e na neutralidade, a sua base institucional. Ou seja, a atividade regulatória pressupõe, além da autonomia, a neutralidade ou exercício de função neutral.

exercício de função neutral. Melhor explicando, o exercício dessa função neutral, passa por agentes reguladores, que não ostentem uma relação partidária, que atuam em espaços legalmente definidos e determinados e que contemplem "conhecimentos técnicos e 
jurídicos específicos, necessários para a satisfação de demandantes requisitos da aplicação da juridicidade" (MOREIRA NETO, 2001, p. 51).

Atividade regulatória no âmbito dos serviços públicos seria, assim, a atividade-fim e multidisciplinar de uma agência reguladora com vistas à manutenção da adequação desse serviço, cuja plena implementação demanda o reconhecimento de sua maior expertise, autonomia e neutralidade, sem os quais não seria possível a sua prevalência seja perante o poder concedente, os concessionários ou os usuários.

A atividade regulatória é eminentemente jurídica porque regulada por lei, mas é, de forma vanguardista, a sede primeira da funcionalização do Direito e, portanto, conjuga não só a aplicação estruturada de normas e princípios jurídicos, mas, acima de tudo, conjuga-as com normas e diretrizes técnicas, com conceitos e princípios econômicos, bem como com análises sociológicas. Nesse sentido, CALANDRI (2008, p. 40) observa que "a regulação pode ser analisada dos pontos de vista da lei em termos de uma função, única perspectiva capaz de lhe assegurar uma coerência". Uma coerência, claro, em função do serviço público regulado e de sua pretendida adequação nos termos da lei.

\section{A IMPOSIÇÃO DE SANÇÕES PELAS AGÊNCIAS REGULADORAS DE SERVIÇOS PÚBLICOS.}

A função sancionatória, como consequência da função jurisdicional, é a esta relacionada e corresponde a uma fase de execução do comando jurisdicional exarado pela própria agência reguladora. Assim, a aplicação de sanções pelo órgão regulador não deixa de ser uma continuidade do exercício da função jurisdicional. Sob o ponto de vista generalista, toda atividade sancionatória decorre de um processo administrativo prévio em que são assegurados o contraditório e a ampla defesa à parte que, supostamente, descumpriu preceito legal ou contratual para com a Administração Pública, que "exerce sanções de polícia administrativa a particulares, culminando na imposição do ato administrativo sancionador" (ARAGÃO, 2013, p. 675). O autor indica como sujeito passivo da atividade sancionatória somente o particular, o que, em seu estudo faz total e absoluto sentido. Todavia, quando se estuda as agências reguladoras, seria possível ocorrer situações de mora do poder concedente frente a seus concessionários e aos usuários dos serviços públicos. Tanto torna possível que o próprio poder concedente figure, de alguma forma, como alvo do exercício do poder sancionatório de uma agência reguladora autônoma e neutra, de fato e de direito. 
Sobre o tema, JUSTEN FILHO (2002, p. 553) salienta a posição de alteridade exercida pelo Estado, na condição de julgador, concluindo que "será possível aludir-se à imparcialidade na acepção acima referida, em que o órgão julgador não acumula a função de julgar com a condição de titular de um dos interesses em conflito”.

A prerrogativa sancionatória é inerente à Administração Pública e às teorias concernentes à sua potestade, como proposto por Hauriou. Entretanto, atualmente, não se pode dissociar a prerrogativa sancionatória dos princípios da proporcionalidade e da finalidade. A função sancionatória das agências reguladoras existe para conferir, em princípio, efetividade à atividade regulatória dessas agências. A função sancionatória poderia ser tida como instrumental. Retorne-se, porém, à questão formulada precedentemente com referência à utilidade da multa aplicada a uma concessionária. $\mathrm{O}$ caráter didático e pedagógico da multa pecuniária tem limites. A reiteração de sua aplicação denota a insubsistência de sua finalidade inicial, subtrai a instrumentalidade propalada e insta os juristas a obter uma solução sucedânea que permita a punição com resultados favoráveis à melhoria ou manutenção da adequação do serviço público. Impor multas pela simples demonstração de poder e da supremacia do interesse público significa desnaturar esse próprio interesse, consubstanciando-se, em verdade, em desvio regulatório.

Não se oponha como óbice intransponível à necessária imposição da sanção a denominada indisponibilidade do interesse público. Refuta a inteligência concluir-se que o interesse público repousa no recebimento de uma multa e não na adequada prestação do serviço público. Vincular o interesse público à aplicação de uma multa como sanção a um concessionário de serviço público é pensamento retrógrado que recusa aos avanços de um Direito Administrativo que, como os demais ramos do Direito previamente evoluídos, busca na consensualidade a solução dos diversos conflitos entre o público e o privado.

Ao atuar com fulcro na prerrogativa sancionatória, os agentes reguladores não devem se preocupar com a vaidade do poder e de sua imposição, mas sim com o bem estar de todos os usuários de um serviço público que, de alguma forma, não vem sendo prestado a contento, seja por descumprimento seja por inadequação do contrato à atualidade. As violações contratuais têm de ser investigadas, obstadas e punidas com rigor, inclusive da declaração de caducidade, mas não podem ser deixados de lado as falhas e anacronismos tecnológicos a que contratos de concessão longevos estão sujeitos. A consensualidade deve ser tida como um norte pela regulação. 
Conforme a doutrina jurídica hoje prevalecente, o Estado Democrático de Direito tem como um dos elementos aptos a robustecê-lo a busca pela decisão de consenso. A função de regulador não é a de se impor sobre concessionárias e usuários, propondo soluções adequadas apenas a suas concepções pessoais ou exclusivamente técnicas. Aquele pedestal da supremacia do interesse púbico e de sua indisponibilidade deve ser usado, apenas, em situações de última instância. Pouco importa a publicação de uma medida dura no diário oficial, se a regulação não for efetiva, (ARAGÃO, 2003, p. 113) “é melhor adotar-se outra medida, menos gravosa, mas que produzida em concertação com os interessados e tenha maiores chances de se efetivar, alcançando mais eficientemente as finalidades públicas colimadas". A regulação deve ser apta a produzir mudanças efetivas e concretas na realidade.

A administração consensual não põe à mesa de negociação o interesse público em si. O que se pretende com as decisões administrativas pela via consensual é não só levar ao debate público dos meios de consecução do interesse público, mas também permitir serem desvelados todos os seus contornos, tornando-o mais palpável à Administração Pública e mais participativo às empresas e aos cidadãos, que têm uma oportunidade de pronunciar-se previamente à fixação de uma política pública. A adoção da consensualidade tem, portanto e ao menos em tese, os meios para resultados mais adequados e de maior eficiência, por conseguinte, ao invés de desafiarem o interesse público, concernentemente à suas supremacia e indisponibilidade, estão a realiza-los e conferir-lhe efetividade e concretude.

A necessidade de se impor uma sanção deve, pois e tal como ensinam MARQUES NETO e CYMBALISTA (2011, p. 16), ser cotejada com outras formas de se obter decisões mais efetivas em dissuadir as condutas indesejadas dos concessionários de serviço. Se há "uma pluralidade de meios que satisfaçam os imperativos regulatórios, deverá o regulador optar por aquele que seja menos gravoso, ou seja, a sanção será o ultimo recurso a ser empregado".

O interesse público na adequação do serviço público é tão superior que é ponto distintivo entre a atividade jurisdicional das agências reguladoras e o poder jurisdicional do Poder Judiciário o princípio conhecido pelo brocardo latino ne procedat judex ex officio. Se se é uma verdade para a atuação do Judiciário, que precisa ser provocado a prestar suas funções, não se aplica em relação às agências reguladoras, que têm o dever de regular o serviço permanentemente. Isto é, diante de algum interesse público porventura violado, os próprios dirigentes da agência, na função de julgadores, podem dar início a um processo administrativo regulatório, independentemente da provocação de uma parte tida como maior interessada. 
Poder-se-ia atualizar aquele brocardo para que contemple a jurisdição administrativa regulatória: regulatio procedat ex offcio.

Mais do que julgar uma "causa" e dar provimento à pretensão deduzida em sede administrativa por uma parte - e não é este o objetivo da jurisdição administrativa regulatória - a agência reguladora prospecta uma decisão com vistas à consecução do interesse público na prestação ininterrupta de um serviço público adequado.

\section{A MUTABILIDADE E A APLICAÇÃO DE SANÇÕES DOS CONTRATOS DE CONCESSÃO PERANTE A LEI No 8.987/1995.}

Os contratos de concessão têm prazos que superam algumas décadas. Se já eram tidos como longos há tempos atrás, atualmente, podem transformar-se numa espécie de freio ao desenvolvimento e de obstáculo intransponível ao serviço adequado. Não à toa Rolland editou quatro enunciados que seriam aplicáveis a todo e qualquer contrato de concessão, conhecidos como "leis de Rolland" (ROLLAND, 1991, pp. 17-18) dentre os quais destaca-se a que preceitua que "as suas regras de organização e de funcionamento podem sempre ser modificados a qualquer momento pela autoridade competente".

O serviço público há de ser constantemente adequado à realidade socioeconômica e tecnológica, garantindo segurança e qualidade em sua prestação. A mutabilidade do contrato de concessão não se configura como uma exceção, mas como uma imperatividade, cabendo primacialmente ao Poder Público a sua mutabilidade como um dever.

Consoante o disposto no $\S 1^{\circ}$ do art. $6^{\circ}$, da Lei $n^{\circ} 8.987 / 95$, serviço adequado é o que satisfaz as condições de regularidade, continuidade, eficiência, segurança, atualidade, generalidade, cortesia na sua prestação e modicidade das tarifas. Como atual, o parágrafo subsequente $\left(\S 2^{\circ}\right)$ entende ser aquele que compreende a modernidade das técnicas, do equipamento e das instalações e a sua conservação, bem como a melhoria e expansão do serviço.

Os dispositivos legais podem ser reunidos, de molde a conceituar-se serviço adequado como aquele que satisfaz as condições de regularidade, continuidade, eficiência, segurança, generalidade, cortesia na sua prestação, modicidade das tarifas e atualidade, compreendida esta como a modernidade das técnicas, do equipamento e das instalações e a sua conservação, bem como a melhoria e expansão do serviço, abrangida, aí, a universalidade. 
A imposição de atualidade é fundamental, eis que, se dessa for destituído, o serviço não será eficiente, perderá em regularidade, oferecerá segurança discutível, podendo estar comprometidas a sua universalização e a própria modicidade das tarifas, eis que sua manutenção será mais cara tanto quanto forem mais antigos os equipamentos disponibilizados. Parece um mero detalhe, mais a atualidade demanda a constante atualização das cláusulas contratuais e suas adequações, inclusive de prazo do contrato, aos investimentos necessários àquela tão propalada e exigida prestação continuada de um serviço adequado.

Vê-se, pois, que a mutabilidade do contrato é inerente às concessões. Portanto, ciente dessa característica fundamental dessa espécie contratual, as agências reguladoras dispõem de um poderoso instrumento para proceder e exigir eventuais alterações contratuais, que podem ser manejadas como um sucedâneo da imposição de sanções pecuniárias, com significativa vantagem para os usuários.

Os contratos de concessão são tidos, destarte, como bem salienta BOCKMAN MOREIRA (2010, p. 32) “institucionalizados em contratos incompletos, qualificados pela respectiva mutabilidade e capacidade de aprendizagem (tecnológica, normativa etc)" . De acrescentar-se a essa definição que dita incompletude é de natureza permanente e continuada, eis que está a permitir permanentes injunções do Poder Concedente ou da autoridade administrativa incumbida em fiscalizar a execução do contrato.

A legitimidade para a prática desses atos de fiscalização da execução do contrato, em princípio, competem ao próprio Poder Concedente, conforme os arts. 29 e 30 da Lei $n^{\circ}$ 8.987/95, sendo possível, porém, àquele Poder, conveniar-se com entidade diversa que passaria a exercer aquelas funções fiscalizatórias, consoante o parágrafo único do precitado art. 30. As agências reguladoras não são meros órgãos físcalizatórios, nem celebram convênios com o Poder Concedente. As agências recebem delegação para atuar por intermédio da lei e sua atuação transcende à de mera fiscalização, pois compete-lhes regular o serviço, o que se constitui num plus considerável. Sua legitimidade para certos atos não podem, entretanto, ser contestada, já havendo a doutrina superado eventuais óbices.

Todavia, o art. 32 consigna a sanção da intervenção do Poder Concedente no serviço para fins de assegurar adequação na prestação do serviço, bem como o fiel cumprimento das normas contratuais, regulamentares e legais pertinentes. Essa intervenção exige uma formalidade preceituada no parágrafo único do art. 32, qual seja a edição de um decreto, que, sabidamente, é ato privativo da Chefia do Executivo. Portanto, em princípio, uma agência reguladora não pode, por ato de seu Colegiado, promover uma intervenção. Porém, esse 
Colegiado poderia e deveria recomendar à Chefia do Executivo a adoção de medidas para intervir no serviço.

O desenvolver do procedimento de intervenção poderá ser atribuído à agência reguladora do serviço, que procederá para os fins do art. 33, deixando, contudo, a decisão final em extinguir a concessão ou devolvê-la ao concessionário para o próprio Poder Concedente, a quem a lei atribuiu dita competência no art. 34 .

Releva sublinhar, dentre as hipóteses contidas nos incisos do art. 35 como de extinção da concessão, a sanção consistente na decretação de sua caducidade, inciso III, por violação dos termos dos incisos do $\S 1^{\circ}$ do art. 38, da Lei de Concessões. O caput do art. 38 deixa a decretação da caducidade "a critério" do Poder Concedente, enquanto seu $\S 1^{\circ}$ utiliza do verbo "poder", parecendo conferir ao Poder Concedente a prática ou não do ato de decretação da caducidade, que se consubstanciaria, assim, num ato discricionário, sujeito ao exame de conveniência e oportunidade daquele.

O dispositivo legal traz dúvidas e, aparentemente, é incongruente para com a exigência de serviço adequado estatuída no art. $6^{\circ}$. De um lado, a declaração de caducidade poderia envolver a ponderação de critérios outros além das falhas na prestação do serviço, como político, financeiro, social e de políticas públicas, a serem avaliados pelo Poder Concedente para decretar ou não a caducidade. Sopesados esses valores, poderia argumentar- se, diante do texto legal vacilante, que o Poder Concedente, motivadamente, poderia deixar de decretar a caducidade por considerá-la mais prejudicial ao interesse público. Nessas hipóteses, a decretação da caducidade teria a natureza jurídica de poder potestativo.

De outra parte, argumento contrário fundar-se-ia na constatação da ineficiência do serviço e de sua total inadequação por culpa da concessionária de serviço público, com grave risco, portanto, à sua qualidade e à segurança dos usuários. Neste caso, ponderados esses critérios, tendo-se por escopo precípuo do interesse público a proteção dos usuários do serviço, seria obrigatória a decretação da caducidade e incorretos estarias tanto o verbo "poder", como a ponderação de critérios conferida ao Poder Concedente, que estaria diante de um dever jurídico e, além de estar obrigado à declaração de caducidade, poderia ser instado a tanto, seja por uma associação de usuários seja pelo Ministério Público.

Os dispositivos colacionados, referentes à intervenção e à caducidade encerram limitações ao exercício da função sancionatória das agências reguladoras, porém, não maculam ou eivam de ilegalidade a sua atuação no exercício dessa prerrogativa sancionatória, 
quanto mais quando atuam em prol da consensualidade ou na melhor consecução do interesse público.

\section{CONCLUSÕES PARA UMA REGULAÇÃO ALÉM DA MERA IMPOSIÇÃO DE SANÇÕES.}

Como visto, por vezes, as falhas na prestação dos serviços públicos decorrem de fatores estranhos à violação de normas contratuais. A caracterização dessa espécie de violação também não é simples e incontestável na prestação de serviços de extrema complexidade.

A natureza das necessidades de máximo interesse público dos usuários dessa espécie de serviço insta a constante adequação do contrato de concessão para a permanente adequação da prestação do serviço público, onde a própria lei exige a sua atualidade. Consequentemente, soluções diversas da aplicação de multas devem ser prospectadas. Enquanto o pagamento de multas nada agrega ao serviço público, senão demonstra somente o poder e a força do Poder Concedente, a substituição dessas penas pecuniárias por sanções outras, de preferência consensuais, que impliquem uma melhoria do serviço e o incremento de sua qualidade e de sua segurança, promovem benefícios em favor da sociedade e, mais proximamente, aos usuários dos serviços, fazendo, inclusive, com que o Concessionário adira espontaneamente às proposições dos entes reguladores.

Assim, sanções que transformassem multas em investimentos maiores que não estivessem previstos em sede contratual ou que determinassem a sua antecipação no tempo contratualmente previsto seriam bem-vindas.

Ao limitar-se a determinar uma determinada concessionária a pagar multas, sem comunicar ao Poder Concedente a respeito das falhas reiteradas detectadas, a agência reguladora não estaria a exercer a função regulatória para a qual foi precipuamente criada, nem permitiria ao Poder Concedente ponderar sobre os critérios que poderiam conduzi-lo seja à decretação da intervenção ou à da caducidade, incidindo em grave erro de atuação. A fiscalização não é a atividade-fim da agência, mas sim um instrumento regulatório. A detecção de falhas do serviço em razão do exercício dessa atividade deve dar origem a um processo regulatório do serviço com vistas ao seu aprimoramento e não à punição pecuniária da concessionária com o consequente incremento da arrecadação de valores em favor da agência. 
Reiteradas faltas punidas com multas pecuniárias demonstram, em síntese, que o serviço é inadequado e que a agência reguladora é incapaz de promover ações tendentes à sua adequação.

Além dos limites ao exercício da função sancionatória das agências reguladoras consignados em lei, anteriormente verificados, surge neste ponto um novo limite lógico fático-legal, que se consubstancia na impossibilidade de as agências reguladoras emitirem multas seguidas e continuadas a uma mesma concessionária. O impeditivo decorre da observação acima realizada quanto ao fato de que se trataria de hipótese de decretação ou de intervenção ou de caducidade pelo Poder Concedente, que, não informado, confia na sua agência reguladora, que, de forma ineficiente e sem exercer a atividade regulatória de que foi incumbida, lhe subtrai o exercício dessas funções legalmente previstas.

\section{REFERÊNCIAS}

ARAGÃO, Alexandre Santos de. Agências Reguladoras e a evolução do Direito Administrativo. Rio de Janeiro, Forense: 2003.

ARAGÃO, Alexandre Santos de. Curso de Direito Administrativo. Rio de Janeiro, Forense: 2013.

ARIÑO ORTIZ, Gaspar. Principios de derecho público econômico: modelo de Estado, gestión pública, regulación económica. Granada: Comares editorial, 2004.

BOBBIO, Norberto. Da estrutura à função: novos estudos de teoria do direito. Barueri - SP, Manole: 2007.

BOCKMAN MOREIRA, Egon. Direito das concessões de serviço público: inteligência da Lei 8.987/1995 (parte geral). São Paulo: Malheiros Editores, 2010.

BRITTO, Carlos Ayres. O regime constitucional dos Tribunais de Contas. In O novo Tribunal de Contas: órgão protetor dos direitos fundamentais, Org. Alfredo José de Souza et al. Belo Horizonte: Fórum, 2005.

CALANDRI, Laurence. Recherche sur la notion de regulation en droit administrative français. Paris: L.G.D.J., 2008.

CASSESE, Sabino. A crise do Estado. Campinas: Saberes Editora, 2010.

CASTELLS, Manuel. A sociedade em rede. São Paulo: Paz e Terra, 2008. 
COMANDUCCI, Paolo. Formas de (Neo)constitucionalismo: um análisis metateórico. In CARBONELL, Miguel (Coord.). Neoconstitucionalismo(s). Madrid: Trotta, 2003.

FERRAZ, Roberto. A macrológica do direito econômico. In Revista de Direito Mercantil n. 142, 2006.

GIANINNI, Massimo Severo. Diritto Pubblico dell'a Economia. Ed. Il Mulino, 1995, p. 299.

JUSTEN FILHO, Marçal. O direito das agências reguladoras independentes. São Paulo: Dialética, 2002.

MACHADO, Santiago Muñoz. Derecho de la regulación: fundamentos e Instrumentos jurídicos de la regulación económica. Madrid: Iustel, 2009.

MARQUES NETO, Floriano de Azevedo. CYMBALISTA, Tatiana Matiello. Os Acordos Substitutivos do Procedimento Sancionatório e da Sanção. Revista Eletrônica de Direito Administrativo Econômico (REDAE), Salvador, Instituto Brasileiro de Direito Público, $\mathrm{n}^{\mathrm{o}}$. 27, agosto/setembro/outubro, 2011. Disponível na Internet: < http://www.direitodoestado.com/revista/REDAE-27-AGOSTO-2011-FLORIANO-

AZEVEDO-TATIANA-MATIELLO.pdf>. Acesso em: 15 de agosto de 2015.

MOREIRA NETO, Diogo de Figueiredo. Poder, Direito e Estado. Belo Horizonte: Ed. Fórum, 2011.

MOTTA, Paulo Roberto Ferreira. Agências reguladoras. Barueri: Atlas, São Paulo, 2003.

ROLLAND, LOUIS. Précis du Droit Administratif. Dalloz, Paris: 1947. 